\title{
Antispasmodic Effect of Blackcurrant (Ribes nigrum L.) Juice and Its Potential Use as Functional Food in Gastrointestinal Disorders
}

\author{
Bojana Miladinovic ${ }^{a}$ Suzana Brankovic ${ }^{b}$ Milica Kostic ${ }^{a}$ Milica Milutinovic ${ }^{a}$ \\ Nemanja Kitic ${ }^{c}$ Katarina Šavikin ${ }^{d}$ Dušanka Kitic ${ }^{a}$ \\ ${ }^{a}$ Department of Pharmacy, Faculty of Medicine, University of Nis, Nis, Serbia; ${ }^{\text {b }}$ Department of Physiology, Faculty of \\ Medicine, University of Nis, Nis, Serbia; ${ }^{C}$ Faculty of Medicine, University of Nis, Nis, Serbia; ${ }^{d}$ Institute for Medicinal \\ Plant Research "Dr Josif Pančic", Belgrade, Serbia
}

\section{Significance of the Study}

- In this study, the relaxative effects of blackcurrant juice were investigated on the gastrointestinal smooth muscle of the rat ileum in vitro. Blackcurrant fruit juice reduced the contractility of the ileum induced by acetylcholine, potassium chloride, calcium chloride, and barium chloride. This antispasmodic effect of blackcurrant juice supports its possible use as a herbal remedy in the management of common gastrointestinal disorders.

\section{Keywords}

Blackcurrant · Spasmolytic activity · Gastrointestinal disorder · Spontaneous contractions · Acetylcholine

\begin{abstract}
Objective: The purpose of this study was to investigate the relaxative effects of blackcurrant juice on the gastrointestinal smooth muscle in vitro. Materials and Methods: Berries of the blackcurrant cultivar Ometa were used for the preparation of the juice used. The spasmolytic activity of blackcurrant juice was tested on rat ileum isolated from male Wistar rats by monitoring its influence on spontaneous contractions, as well as contractions induced by potassium chloride $(\mathrm{KCl})$, barium chloride $\left(\mathrm{BaCl}_{2}\right)$, calcium chloride $\left(\mathrm{CaCl}_{2}\right)$, and
\end{abstract}

acetylcholine (Ach). The results are expressed as the mean \pm standard deviation obtained in 6 measurements and statistical significance was determined by the Student $t$ test, with $p<0.05$ taken as significant. Results: The blackcurrant cultivar Ometa significantly reduced the frequency and the amplitude of spontaneous contractions $(57.94 \pm 3.44 \%)$ and Ach-induced contractions $(42.74 \pm 5.36 \% ; p<0.05)$ of the isolated rat ileum. Cumulative concentrations $(0.01-3 \mathrm{mg} /$ $\mathrm{mL}$ ) of the Ometa juice also reduced contractions of the isolated rat ileum stimulated by $\mathrm{KCl}(51.46 \pm 6.87 \%), \mathrm{CaCl}_{2}$ (57.54 $\pm 6.47 \%)$, and $\mathrm{BaCl}_{2}$ (58.54 $\left.\pm 10.55 \%\right)$. The inhibitory effects of the juice were proportional to the applied concentration. Conclusion: The antispasmodic effect of Ometa cultivar shows that common gastrointestinal disorders could be treated by the functional food.

(c) 2018 The Author(s)

Published by S. Karger AG, Basel

\begin{tabular}{ll}
\hline KARGER & $\begin{array}{l}\text { @ } 2018 \text { The Author(s) } \\
\text { Published by S. Karger AG, Basel }\end{array}$ \\
$\begin{array}{l}\text { Openger } \\
\text { E-Mail karger@karger.com }\end{array}$ & $\begin{array}{l}\text { This is an Open Access article licensed under the Creative Commons } \\
\text { Attribution-NonCommercial-4.0 International License (CC BY-NC) } \\
\text { www.karger.com/mpp }\end{array}$ \\
$\begin{array}{l}\text { (http://www.karger.com/Services/OpenAccessLicense), applicable to } \\
\text { the online version of the article only. Usage and distribution for com- } \\
\text { mercial purposes requires written permission. }\end{array}$
\end{tabular}

Dušanka Kitic

Department of Pharmacy, Faculty of Medicine

University of Nis, Ave Zorana Djindjica 81

RS-18000 Nis (Serbia)

E-Mailduska@medfak.ni.ac.rs 


\section{Introduction}

The gastrointestinal tract is a system responsible for the intake and digestion of food, absorption of nutrients, and the elimination of end products of food digestion. Functional disorders of the gastrointestinal system include the symptoms manifested in the mid or lower part of the digestive tract that cannot be attributed to anatomical or biochemical dysfunctions $[1,2]$. These disorders comprise approximately $40 \%$ of diagnosed gastrointestinal problems [3]. Functional dyspepsia is the most common dysfunction of the upper digestive tract, and irritable bowel syndrome of the lower part [4]. However, functional gastrointestinal disorders are a consequence of a combination of the predisposing genetic factors, environmental conditions, and composition and/or function of the intestinal microbiota $[5,6]$. Food plays an essential role both in the development and prevention of these disorders.

Blackcurrant (Ribes nigrum L., Grossulariaceae) is a plant species grown domestically and commercially for its aromatic berries. Studies on the chemical composition of blackcurrant fruit revealed that these berries are rich in different classes of flavonoids, such as anthocyanins (delphinidin-3-O-rutinoside, cyanidin-3-O-rutinoside), flavonols (myricetin, quercetin), phenolic acids (chlorogenic and neochlorogenic acid), flavanols (epicatechin and catechin), as well in vitamin C. Flavonoids make up a third of the total phenol content and a dominant group of flavonoids are anthocyanins $[7,8]$. Due to the high anthocyanin content, this plant species is used as a natural colorant in the food industry.

Blackcurrant is used in traditional European medicine for the treatment of rheumatic diseases, hypertension, diabetic neuropathy, neoplastic, and neurodegenerative diseases $[9,10]$. Blackcurrant increases the level of highdensity lipoprotein cholesterol and lowers plasma triglycerides and total cholesterol [11]. Currant seed oil has been reported to reduce the levels of inflammatory markers in the serum [12], and to act as a potential anticoagulant [13].

Experiments had shown that blackcurrant leaf extract reduced platelet aggregation, significantly increased the cell viability in lower doses of polyphenols, and increased the CD39-positive fraction of endothelial cells and nitric oxide synthase activation [14]. Extracts of blackcurrant fruit and leaves extracts increase the resistance of red blood cell membranes against free radicals [15]. Blackcurrant flavonoids exhibit phytoestrogen activity [16].
Flavonoids, which are abundant in blackcurrants, have been shown to cause the relaxation of the smooth muscle [17-20]. Therefore, the aim of this paper was to investigate the effects of blackcurrant juice on spontaneous motility and contractility on the intestinal smooth muscle of rats in vitro.

\section{Materials and Methods}

\section{Plant Material and Sample Preparation}

The fruits of blackcurrant $(R$. nigrum L.) cultivar Ometa were hand-picked from June to July 2010 in the experimental field of the Faculty of Agriculture in Belgrade, located in Mislodin, the region of Obrenovac, Serbia. The juices were obtained manually from the fresh, undamaged fruits, and then centrifuged for $10 \mathrm{~min}$ at $8,050 \mathrm{~g}$. Supernatants were stored in closed containers at $-18^{\circ} \mathrm{C}$ and dissolved in Tyrode solution to the desired concentration when needed. Tyrode solution consisted of $150 \mathrm{mM} \mathrm{NaCl}, 2.7 \mathrm{mM}$ $\mathrm{KCl}$ (potassium chloride), $2 \mathrm{mM} \mathrm{MgCl}, 1.8 \mathrm{mM} \mathrm{CaCl}_{2}$ (calcium chloride), $0.4 \mathrm{mM} \mathrm{NaH}_{2} \mathrm{PO}_{4}, 12 \mathrm{mM} \mathrm{NaHCO}_{3}$, and $5.5 \mathrm{~mm}$ of glucose.

\section{Experimental Animals}

Male Wistar rats (200-250 g, 12 weeks old) were obtained from the vivarium of the Faculty of Medicine, University of Nis, Serbia. The rats had been matured under standard laboratory conditions (temperature $20-24^{\circ} \mathrm{C}$, with a 12 -h light cycle) and had free access to food and water. All animal experiments were done in accordance with the Council of Europe Directive of 22nd September, 2010 (Directive 2010/63/EU), and were approved by the Animal Ethics Committee of the Faculty of Medicine, University of Nis (decision No. 01-206-7).

\section{Experimental Design}

Four segments of the each rat ileum were used in the experiments. The animals were anesthetized by ether and the abdominal cavity opened. The segments of the distal parts of the ileum were dissected out. Then 2 -cm-long segments of the rat ileum were placed in a bath filled with Tyrode solution, aerated with a mixture of $5 \%$ carbon dioxide and oxygen, and heated to $37^{\circ} \mathrm{C}$. Contractions of the isolated ileum were measured using a transducer (TSZ04-E, Experimetria Ltd, Budapest, Hungary) and analyzed using the SPEL Advanced ISOSYS Data Acquisition System (Experimetria Ltd). Once the ileum segments were placed in a bath, adaptation to conditions lasted $30 \mathrm{~min}$ before the start of the experiment. The increasing concentrations of juice $(0.01-3 \mathrm{mg} / \mathrm{mL})$ were added to the organ bath directly. After each series of experiments, the tissue was rinsed with Tyrode solution and stabilized for $10 \mathrm{~min}$. A concentration-response curve was obtained by the cumulative addition of the juices that were added in 15-min intervals, so the tissue was exposed to juices for $1.5 \mathrm{~h}$.

A cumulative impact of the blackcurrant juice $(0.01-3 \mathrm{mg} / \mathrm{mL})$ on the spontaneous contractions of the rat ileum was measured in the first experimental series. Papaverine was used as a positive control $(0.01-3 \mu \mathrm{g} / \mathrm{mL})$. Results are presented as the percentage change of the basal tone compared with baseline values (\% of inhibition of ileal contractility). 




Fig. 1. a Recordings of cumulative concentration-response curves of the blackcurrant ( $R$. nigrum L.) variety Ometa juice. b Graph showing the contractile effect of the blackcurrant juice on the spontaneous activity of the isolated rat ileum. Papaverine was used as a positive control. Each point represents the mean percentage values with respect to spontaneous contractions in Tyrode solution (control) $\pm \mathrm{SD}$ of 6 segments. ${ }^{*} p<0.05,{ }^{* *} p<0.01$ versus Tyrode.

The mechanism of the relaxant effects of blackcurrant juice on ileum contractility was assessed in the second experimental series. Acetylcholine (Ach; 5-1,500 nM; $0.1 \mathrm{~mL}$ ) was cumulatively added to the bath, in the absence or presence of the juice $(1-3 \mathrm{mg} / \mathrm{mL})$. The effect of blackcurrant juice on Ach-induced contraction of the ileum is expressed as the percentage reduction of contractions compared to the control series (when only Ach was applied in the absence of juice). Atropine (140 nM), a nonselective muscarinic receptor blocking agent, was used as a positive control.

The third experimental series examined the effect of the blackcurrant juice on calcium channel activity of the rat ileum. The smooth muscles of the ileum were contracted with a depolarizing solution of $\mathrm{KCl}(80 \mathrm{mM})$. A high concentration of $\mathrm{K}^{+}$induced tonic contractions of the intestine, which followed the cumulative addition of the blackcurrant juice $(0.01-3 \mathrm{mg} / \mathrm{mL})$. The same procedure was repeated with verapamil $(0.015-1.5 \mu \mathrm{g} / \mathrm{mL})$, a calcium channel blocker. The relaxation of potassium-induced contractions of the ileum by blackcurrant juice is expressed as a percentage of the reduced contraction caused by potassium ions, without the addition of the juice.

The impact of the blackcurrant juice on barium chloride $\left(\mathrm{BaCl}_{2}\right)$-induced contractions $(3-900 \mu \mathrm{M})$ of the rat ileum was also examined. Contractions were induced by $\mathrm{CaCl}_{2}$ in $\mathrm{Ca}^{2+}$-free medium. Cumulative concentration-response curves of $\mathrm{Ca}^{2+}$ were obtained by cumulatively adding $\mathrm{CaCl}_{2}$ in the absence and presence of the juice ( 1 and $3 \mathrm{mg} / \mathrm{mL})$ and verapamil $(0.3 \mu \mathrm{mol} / \mathrm{L})$.

Spasmolytic Activity of Blackcurrant Juice



Fig. 2. a Recordings of Ach-induced contractions of the isolated rat ileum. b Graph showing the effects of the blackcurrant juice and atropine on the Ach-induced contractions of isolated rat ileum. Curves showing the values of control, Ach + blackcurrant juice $(1 \mathrm{mg} / \mathrm{mL})$, Ach + blackcurrant juice $(3 \mathrm{mg} / \mathrm{mL})$, and Ach + atropine (as a positive control), respectively. Each point represents the mean values in percent of maximal response \pm SD of 6 segments. ${ }^{*} p<0.05,{ }^{* *} p<0.01$ versus control.

\section{Statistical Analysis}

Data were statistically analyzed and expressed as the mean \pm standard deviation (SD) obtained in 6 measurements. Statistical significance was determined by the Student $t$ test, with $p<0.05$ taken as significant. The effective concentration $\mathrm{EC}_{50}$ (concentration that causes $50 \%$ of maximal response) was obtained by a regression analysis. Statistical significance of inhibitory effects caused by use of blackcurrant juice was examined by the Student $t$ test. Significant statistical differences among $\mathrm{EC}_{50}$ values were obtained by one-way ANOVA or Student $t$ test. Analyses were performed using the SPSS statistical software package (v.20.0; SPSS, Chicago, IL, USA).

\section{Results}

Juice from blackcurrant cultivar Ometa significantly reduced the spontaneous contractions of the isolated rat ileum in a dose-dependent manner. The highest concentration of blackcurrant juice used in this study, i.e., $3 \mathrm{mg} /$ $\mathrm{mL}$, significantly decreased ileum contraction $(p<0.01$; Fig. 1). The $\mathrm{EC}_{50}$ value for this concentration was $3.23 \pm$ $0.11 \mathrm{mg} / \mathrm{mL}$. 


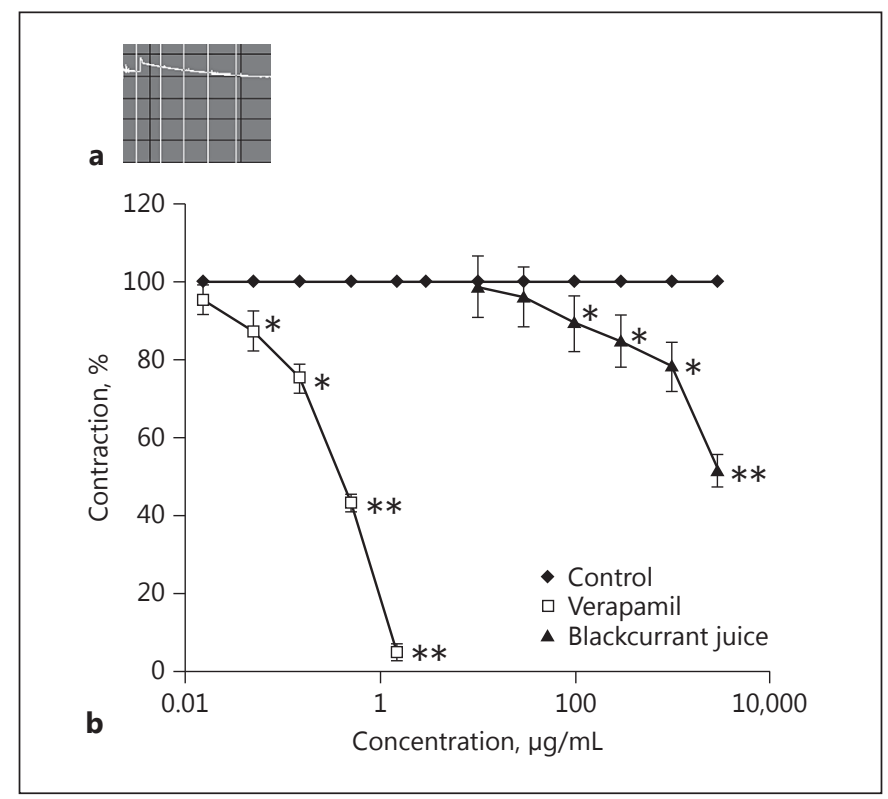

Fig. 3. a Recordings of $\mathrm{KCl}$-induced contractions of the isolated rat ileum. $\mathbf{b}$ Graph showing the effects of the blackcurrant juice on the $\mathrm{KCl}$-induced contractions of the isolated rat ileum. Verapamil was used as a positive control. Each point represents the mean values in percent of maximal response $\pm \mathrm{SD}$ of 6 segments. ${ }^{*} p<0.05$, ** $p<0.01$ versus control.

In the second experimental series, blackcurrant juice significantly inhibited the Ach-induced contraction of the ileum (Fig. 2) proportional to the applied concentrations. Ometa juice $(3 \mathrm{mg} / \mathrm{mL})$ decreased the contractility of the ileum $(56,495.53 \pm 633.34$ vs. $131,294.76 \pm 11,816.02$; $p<0.01)$. The $\mathrm{EC}_{50}$ value for Ach $(0.15 \pm 0.05 \mathrm{nM})$ was increased in the presence of juice to $7.64 \pm 3.01 \mathrm{nM}$. Atropine inhibited the stimulative effects of Ach $(21,033.29 \pm$ $1,261.39$ vs. $131,294.76 \pm 11,816.02 ; p<0.01)$.

Cumulative concentrations of Ometa juice inhibited contractions of the isolated rat ileum stimulated by $\mathrm{KCl}$ $(p<0.01)$, with $\mathrm{EC}_{50}$ values of $3.04 \pm 0.42 \mathrm{mg} / \mathrm{mL}$ (Fig. 3 ). Verapamil, a calcium channel blocker, relaxed KCl-induced contractions of the ileum $(p<0.01)$.

The effects of the juice and verapamil on $\mathrm{Ca}^{2+}$-stimulated contractions of the rat ileum in the absence of $\mathrm{CaCl}_{2}$ are shown in (Fig. 4). Ometa juice inhibited $\mathrm{Ca}^{2+}{ }_{-}$ stimulated contractions of the isolated rat ileum $(p<$ 0.01 ). Verapamil, a calcium channel blocker, also caused the inhibition of $\mathrm{Ca}^{2+}$-induced contraction of the ileum. The $\mathrm{EC}_{50}$ value for calcium ions $(0.61 \pm 0.09 \mathrm{mM})$ was increased in the presence of Ometa juice $(1.61 \pm 0.31$ $\mathrm{mM})$.

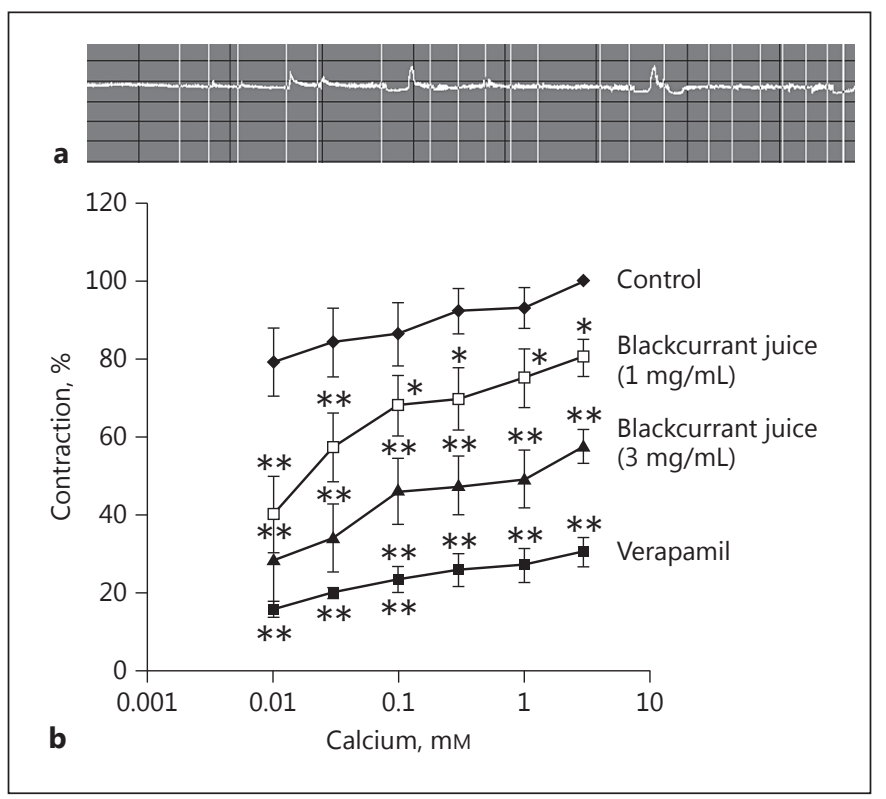

Fig. 4. a Recordings of $\mathrm{Ca}^{2+}$-induced contractions of the isolated rat ileum. $\mathbf{b}$ Graph showing the effects of the blackcurrant juice on $\mathrm{Ca}^{2+}$ dose-response curves of the isolated rat ileum. Verapamil was used as a positive control. $\mathrm{Ca}^{2+}$ was added in a cumulative concentration in $\mathrm{Ca}^{2+}$-free medium. Each point represents the mean values in percent of maximal response \pm SD of 6 segments. ${ }^{*} p<0.05$, ** $p<0.01$ versus control.

The juice significantly reduced $\mathrm{BaCl}_{2}$-stimulated contraction of the isolated rat ileum in a concentration-dependent manner (Fig. 5). A concentration of $3 \mathrm{mg} / \mathrm{mL}$ induced significant relaxation $(p<0.01)$. The $\mathrm{EC}_{50}$ value for $\mathrm{BaCl}_{2}(7.03 \pm 0.82 \mu \mathrm{M})$ was increased to $518.29 \pm 62.69$ $\mu \mathrm{M}$ in the presence of the juice $(3 \mathrm{mg} / \mathrm{mL})$.

All the experiments were conducted in parallel with the control, using the same animal tissue. Significant statistical differences (one-way ANOVA test) were found among the $\mathrm{EC}_{50}$ values of the juice, standards, and appropriate controls in Ach-, $\mathrm{BaCl}_{2-}^{-}$, and $\mathrm{CaCl}_{2}$-induced contractions $(p<0.001)$. The Student $t$ test was used for the comparison of $\mathrm{EC}_{50}$ of the juice and papaverine or verapamil for spontaneous and $\mathrm{KCl}$-induced contractions, respectively $(p<0.001)$, and significant statistical differences were obtained $(p<0.001)$.

\section{Discussion}

In this study, blackcurrant juice has been shown to significantly reduce the contractility of smooth muscles of the rat ileum and to exert a spasmolytic effect. The relax- 


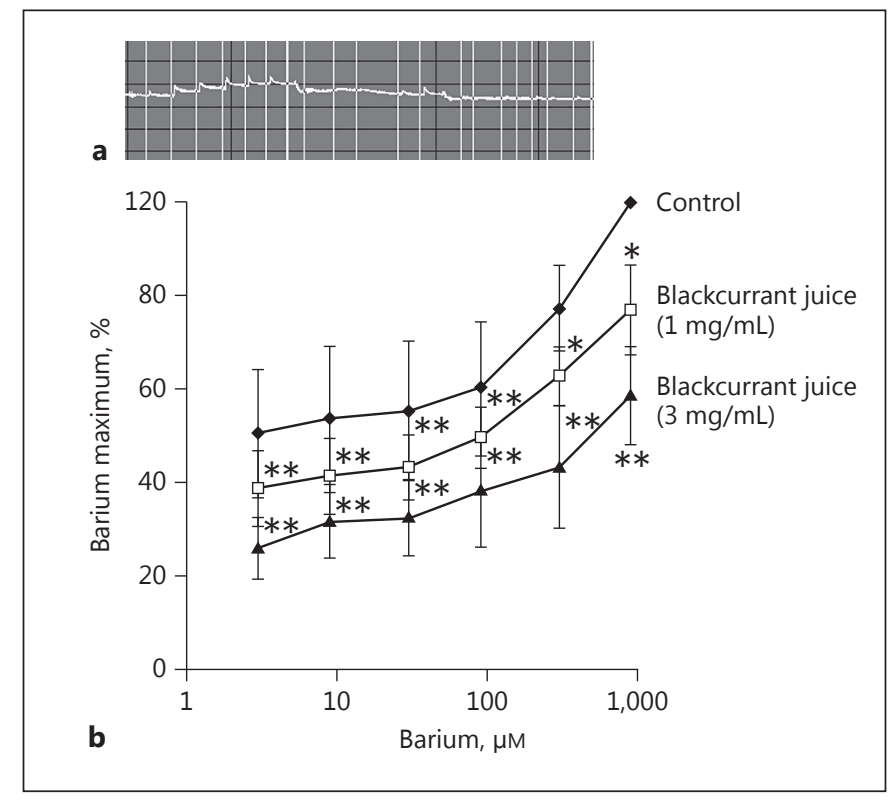

Fig. 5. a Recordings of $\mathrm{BaCl}_{2}$-induced contractions of the isolated rat ileum. $\mathbf{b}$ Graph showing the concentration-response curves of $\mathrm{BaCl}_{2}$ in the absence and presence of the blackcurrant juice in the isolated rat ileum preparations. Each point represents the mean values in percent of maximal response \pm SD of 6 segments. ${ }^{*} p<$ $0.05,{ }^{* *} p<0.01$ versus control.

ant effects of the juice were reversed after washing of the tissue, showing that spasmolytic effects were not due to intestinal damage.

Spontaneous contractions of ileum smooth muscle are induced by cyclic depolarization due to the entry of calcium ions into the cells and the activation of contractile proteins. Contractility of the gastrointestinal system is regulated by a number of physiological mechanisms. Nervous and humoral factors, more precisely neurotransmitters of the enteric nervous system, regulate the spontaneous rhythmic contraction and relaxation of smooth muscles of the intestine. The enteric nervous system (brain-in-the-gut) is essential for normal motility of the small intestine [21]. It is known that extracts which affect the contractility of the intestine, have neurophysiological activity $[22,23]$. Also, cholinergic antagonists have been used to decrease intestinal motility [24]. In order to verify the presence of cholinergic components in blackcurrant juice, we monitored its effect on Ach-induced contractions of the ileum.

In order to verify the presence of cholinergic components in the blackcurrant juice, we monitored its effect on Ach-induced contractions of the ileum. Ach caused dose- dependent contractions of the ileum and achieved maximal effect $30 \mathrm{~s}$ after application. Ometa juice showed significant inhibitory effects on Ach-stimulated contractions of the rat ileum. The inhibitory effects of the juice were proportional to the applied concentration and reversible after rinsing the tissue with Tyrode solution. Ach, the most common neurotransmitter of the gastrointestinal system, increases intestinal muscle contractility. In the digestive tract, Ach activates nicotinic receptors, which are present in vegetative ganglia, or muscarinic receptors found on smooth muscles and parasympathetic nerve fibers [25]. The stimulation of muscarinic receptors on the membrane of smooth muscles increases the intracellular calcium concentration [26-28]. Muscarinic receptors in the smooth muscles induce signal transduction mediated by G-protein and activate phospholipase-C, resulting in the production of inositol-triphosphate and diacylglycerol. Inositol-triphosphate increases the concentration of calcium ions in the cell [29].

Blackcurrant juice also caused significant relaxation of the ileum stimulated by high concentrations of $\mathrm{KCl}$. High concentrations of potassium ions are known to cause tonic contraction of the smooth intestinal muscles, causing the opening of voltage-dependent L-type calcium channels, allowing the entry of calcium ions into the cell [30]. Therefore, substances that inhibit contractions induced by high $\mathrm{K}^{+}$concentrations are considered calcium channel blockers [31]. Ometa juice also inhibited contractions of the ileum smooth muscle stimulated by $\mathrm{CaCl}_{2}$ in the absence of calcium ions. Verapamil, a calcium channel blocker, has also inhibited the ileum $\mathrm{CaCl}_{2}$-stimulated contractions. The results of the calcium ion-stimulated inhibition of contraction suggest that blackcurrant juice contains ingredients that can inhibit calcium channels. We observed that blackcurrant juice inhibited the $\mathrm{BaCl}_{2}$ induced contraction of the ileum. Barium causes the depolarization of smooth muscle, which results in the opening of voltage-dependent calcium channels and the entry of calcium ions into cells [30].

Phytochemical analysis of blackcurrant cultivar Ometa has shown the presence of flavonoids, with myricetin as the dominant flavonol [32], and cyanidin-3-O-rutinoside as the dominant anthocyanin as well as vitamin C [7]. The juice contains polyphenols, flavonoids, and anthocyanins, and possesses good antioxidative activity $[7,32]$. It is also a valuable antimicrobial and antifungal agent. Flavonoids, the main components of numerous plant extracts, have been shown to cause relaxation of the smooth musculature in various animal species. The spasmolytic effect of flavonoids has been demonstrated on the ileum 
[17-20], bronchi, and the uterus of rats [33] in vitro and in vivo. Quercetin, one of the flavonoids found in blackcurrant juice, has been shown to have an inhibitory effect on the spontaneous contractions of rabbit duodenum [34]. Quercetin has produced a relaxant effect on isolated guinea pig ileum previously contracted by high concentrations of $\mathrm{K}^{+}$, and has inhibited intestinal contraction induced by different concentrations of calcium, showing a calcium-antagonistic effect [35]. Our results are consistent with such previous studies.

\section{Conclusion}

Blackcurrant (R. nigrum L.) cultivar Ometa fruit juice significantly reduced the contractility of the ileum smooth muscle. The juice inhibited spontaneous contractions, as well as contractions induced by $\mathrm{Ach}, \mathrm{KCl}$, $\mathrm{CaCl}_{2}$, and $\mathrm{BaCl}_{2}$. Hence, blackcurrant juice could have antispasmodic activity that might be used as a herbal remedy to reduce the contractility of the gastrointestinal system.

\section{Acknowledgements}

This research was supported by the Ministry of Education, Science and Technological Development of the Republic of Serbia (grant No. III 46013 and III 41018). The authors are also grateful for the financial support of the Internal Project of the Faculty of Medicine, University of Nis, Serbia, No. 25, named "Chemical Characterization, Biological Activity and Nutritional Value of Ribes nigrum L, Salvia sclarea L., and Foeniculum vulgare Miller." The authors would like to thank Mr. Aleksandar Jovanovic for his support and expertise in English.

\section{Disclosure Statement}

The authors have no conflicts of interest to disclose.

\section{References}

1 Corazziari E: Definition and epidemiology of functional gastrointestinal disorders. Best Pract Res Clin Gastroenterol 2004;18:613631.

2 Quigley EMM: Functional gastrointestinal disorders in adults; in Guarino A, Quigley EMM, Walker WA (eds): Probiotic Bacteria and Their Effect on Human Health and WellBeing. World Review of Nutrition and Dietetics. Basel, Karger, 2013, vol 107, pp 87-94.

3 Parkman HP, Doma S: Importance of gastrointestinal motility disorders. Pract Gastroenterol 2006;30:23-40.

4 Khan I, Samson SE, Grover AK: Antioxidant supplements and gastrointestinal diseases: a critical appraisal. Med Princ Pract 2017;26: 201-217.

5 Drossman DA: The functional gastrointestinal disorders and the Rome III process. Gastroenterology 2006;130:1377-1390.

6 Foster JA, Lyte M, Meyer E, et al: Gut microbiota and brain function: an evolving field in neuroscience. Int J Neuropsychopharmacol 2016;19:pyv114.

7 Miladinovic B, Kostić M, Šavikin K, et al: Chemical profile and antioxidative and antimicrobial activity of juices and extracts of 4 black currants varieties (Ribes nigrum L.). J Food Sci 2014;79:301-309.

8 Šavikin K, Mikulič-Petkovšek M, Djordjević $B$, et al: Influence of shading net on polyphenol profile and radical scavenging activity in different varieties of black currant berries. Sci Hortic 2013;160:20-28.
9 Tabart J, Franck T, Kevers C, et al: Antioxidant and anti-inflammatory activities of Ribes nigrum extracts. Food Chem 2012;131:11161122 .

10 Gopalan A, Reuben SC, Ahmed S, et al: The health benefits of blackcurrants. Food Funct 2012;3:795-809.

11 Zhu Y, Xia M, Yang Y, et al: Purified anthocyanin supplementation improves endothelial function via NO-cGMP activation in hypercholesterolemic individuals. Clin Chem 2011; 57:1524-1533.

12 Tahvonen RL, Schwab US, Linderborg KM, et al: Black currant seed oil and fish oil supplements differ in their effects on fatty acid profiles of plasma lipids, and concentrations of serum total and lipoprotein lipids, plasma glucose and insulin. J Nutr Biochem 2005; 16 : 353-359.

13 Stone DA, Hawke MW, LaMonte M, et al: Ulcerated atherosclerotic plaques in the thoracic aorta are associated with cryptogenic stroke: a multiplane transesophageal echocardiographic study. Am Heart J 1995;130:105108.

14 Luzak B, Boncler M, Rywaniak J, et al: Extracts from Ribes nigrum leaves in vitro activates nitric oxide synthase (eNOS) and increases CD39 expression in human endothelial cells. J Physiol Biochem 2014;70:10071019.

15 Bonarska-Kujawa D, Cyboran S, Zylka R, et al: Biological activity of blackcurrant extracts (Ribes nigrum L.) in relation to erythrocyte membranes. Bio Med Res Int 2014;2014: 783059 .
16 Nanashima N, Horie K, Tomisawa T, et al: Phytoestrogenic activity of blackcurrant (Ribes nigrum) anthocyanins is mediated through estrogen receptor alpha. Mol Nutr Food Res 2015;59:2419-2431.

17 Meli R, Autore G, Dicarlo G, et al: Inhibitory action of quercetin on intestinal transit in mice. Phytother Res1990;4:201-202.

18 Di Carlo G, Mascolo N, Izzo A, et al: Effects of quercetin on the gastrointestinal tract in rats and mice. Phytother Res 1994;8:42-45.

19 Hammad H, Abdalla S: Pharmacological effects of selected flavonoids on rat isolated ileum: structure-activity relationship. Gen Pharmacol 1997;28:767-771.

20 Revuelta M, Cantabrana B, Hidalgo A: Depolarization-dependent effect of flavonoids in rat uterine smooth muscle contraction elicited by $\mathrm{CaCl}_{2}$. Gen Pharmacol 1997;29:847857.

21 Wood JD: Enteric nervous system: neuropathic gastrointestinal motility. Dig Dis Sci 2016;61:1803-1816.

22 Pilija V, Radenkovic M, Djurendic Brenesel $\mathrm{M}$, et al: Inhibitory effect of Ginkgo biloba extract on the tonus of the small intestine and the colon of rabbits. Molecules 2010;15:20792086.

23 Radenkovic $M$, Ivetic $\mathrm{V}$, Popovic $\mathrm{M}$, et al: Neurophysiological effects of mistletoe (Viscum album L.) on isolated rat intestines. Phytother Res 2006;20:374-377. 
24 Hunt R: Evolving concepts in functional gastrointestinal disorders:promising directions for novel pharmaceutical treatments. Best Pract Res Clin Gastroenterol 2002;16:869883.

25 Radenkovic M, Samardzic R, Veljkovic S, et al: Regional differences in motor responsiveness to hyoscine butylbromide in rabbit isolated small and large intestine. Facta Univ 2003;10:84-87.

26 Eglen M, Hedge S, Watson N: Muscarinic receptor subtypes and smooth muscle function. Pharmacol Rev 1996;48:531-565.

27 Elorriaga M, Anselmi E, Hernandez JM, et al: The source of $\mathrm{Ca}^{2+}$ for muscarinic receptorinduced contraction in rat ileum. J Pharm Pharmacol 1996;48:817-819.

28 Gilani A, Khan A, Ghayur M, et al: Antispasmodic effects of Rooibos tea (Aspalathus lin- earis) is mediated predominantly through $\mathrm{K}^{+}$channel activation. Basic Clin Pharmacol Toxicol 2006;99:365-373.

29 Kirschstein T, Rehberg M, Bajorat R, et al: High $\mathrm{K}^{+}$-induced contraction requires depolarization-induced $\mathrm{Ca}^{2+}$ release from internal stores in rat gut smooth muscle. Acta Pharmacol Sin 2009;30:1123-1131.

30 Mori MX, Itsuki K, Hase H, et al: Dynamics of receptor-operated $\mathrm{Ca}^{2+}$ currents through TRPC channels controlled via the $\mathrm{PI}(4,5) \mathrm{P}_{2}$ PLC signaling pathway. Front Pharmacol 2015;6:22.

31 Brankovic S, Kitic D, Radenkovic M, et al: Calcium blocking activity as a mechanism of the spasmolytic effect of the essential oil of Calamintha glandulosa Silic on the isolated rat ileum. Gen Physiol Biophys 2009;28:174178.
32 Miladinovic B, Stojanovic D, Kostić M, et al: Flavonoid content of black currant (Ribes nigrum L.) juices; in: 49th Days of Preventive Medicine: Book of Abstracts. September 22-25, 2015. Niš, Public Health Institute, pp 61-63.

33 Rotondo A, Serio R, Mule F: Gastric relaxation induced by apigenin and quercetin: analysis of the mechanism of action. Life Sci 2009;85:85-90.

34 Santos-Fagundes D, Grasa L, Gonzalo S, et al: Different mechanisms of actions of genistein and quercetin on spontaneous contractions of rabbit duodenum. Rev Esp Enferm Dig 2015; 107:413-416.

35 Morales MA, Tortoriello J, Meckes M, et al: Calcium-antagonist effect of quercetin and its relation with the spasmolytic properties of Psidium guajava L. Arch Med Res 1994;25: $17-21$. 